\title{
Peptide based amphiphiles
}

\author{
Dennis W. P. M. Löwik* and Jan C. M. van Hest \\ Department of Organic Chemistry, University of Nijmegen, Toernooiveld 1-U177, 6525 ED \\ Nijmegen, The Netherlands. E-mail: lowik@sci.kun.nl; Fax: +31(0)243653393; \\ Tel: $+31(0) 243652325$
}

Received 5th November 2003

First published as an Advance Article on the web 19th March 2004

\section{Introduction}

Amphiphilicity is one of the main driving forces for self-assembly. Molecules containing both polar and apolar elements tend to minimize unfavourable interactions with the aqueous environment via an aggregation process, in which the hydrophilic domains become exposed and the hydrophobic moieties remain shielded. Based on parameters such as amphiphile geometry and concentration a variety of assemblies can be formed, from micellar aggregates to bilayer structures such as vesicles. Common amphiphiles are single chain surfactants such as fatty acids, and dialkylated species such as phospholipids, the latter being the main constituents of for instance cell membranes. However, amphiphilic behaviour is also quite regularly observed in proteins and peptides. There is often a clear relationship between the amphiphilic character of a protein or peptide and its function. Most of the time amphiphilic peptides display their activity at the cell membrane interface, either in a constructive way, e.g. by cell signal transduction or in a more detrimental way by destroying the integrity of the cell membrane. The self-assembling properties induced by the amphiphilic character are therefore mandatory to create functionality. The interplay between structural organisation and biological activity has intrigued many researchers in the field of bio-organic and supramolecular chemistry for quite some time already. Recently, however, the research area of peptide amphiphiles has experienced a strong increase in activity, many new structures have been synthesised and their structural and functional features explored. Incorporation of chemical and biochemical functionality into amphiphilic peptides has led to the development of new surfactants with unprecedented properties leading to novel applications in the fields of materials and biomedical research. ${ }^{1}$

In this review paper we constrain ourselves to three categories of amphiphilic peptides, i.e. 1) true peptide amphiphiles consisting solely of (natural) amino acids, 2) peptides containing non-amino acid hydrophobic elements by connecting one or more long alkyl chains or phospholipids to a peptide sequence, 3) peptide based block copolymers, i.e. polymers constructed entirely from amino acids, as well as hybrid systems combining polypeptides with synthetic polymers. The major recent developments in all three categories will be discussed, with an emphasis on structureproperty relationships. Self-assembling peptides, whose behaviour cannot merely be attributed to amphiphilicity, ${ }^{2}$ are beyond the scope of this review. Also membrane proteins will not be discussed as they constitute a whole category of amphipathic structures that deserve a review of their own.

\section{All-amino acid peptide amphiphiles}

Peptides (and proteins) performing a specific task in biological membranes, such as pore formation, membrane fusion or signal transduction, need to be amphiphilic, reflecting the nature of the environment they reside in. An important class of amphiphilic peptides, solely constituted of amino acids, is organized in so-called amphipathic sequences, which means they are comprised of both hydrophobic and hydrophilic domains when the peptide is appropriately folded. To allow the apolar moieties to interact with the membrane interior and to expose the polar residues to the aqueous environment, the peptides fold into helices and sheets. Furthermore, it is often observed that amphiphilic peptides selfassemble in a lipid bilayer to further optimize their interaction with the surroundings. A number of toxins like magainins ${ }^{3}$ and antibiotics such as Gramicidin $\mathrm{S}^{4}$ belong to this class of peptide amphiphiles, and act by forming pores in the membranes they associate with. Rapid, peptide-induced membrane permeabilization is an effective mechanism of antimicrobial action, but unfortunately most of the natural amphiphilic peptides do not possess properties compatible with use as antibiotics, e.g. due to their indiscriminate toxicity. Therefore, a lot of research has focused on the design of all-amino acid based amphiphilic model compounds to obtain a better understanding of their assembly behaviour and
Dennis Löwik was born in 1969. After completing his MSc in organic chemistry in 1994, he received his PhD in 1998 at Utrecht University with Prof. Dr. Rob Liskamp. This was followed

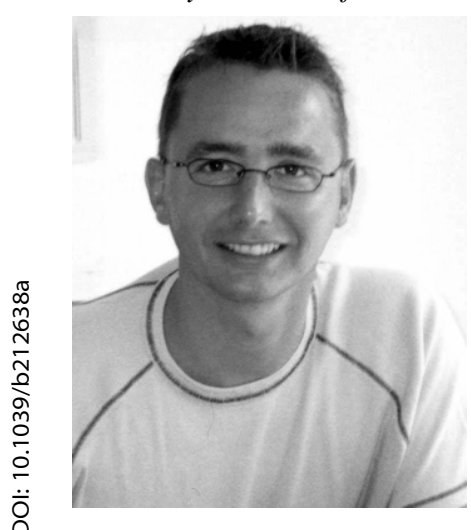
by a post-doctoral position at the Institute of Biotechnology at the University of Cambridge with Prof. Chris Lowe. In 2000 he joined the group of Prof. Bert Meijer at Eindhoven University. From 2001 to date he is appointed at the University of Nijmegen in the bio-organic chemistry group of Prof. Jan van Hest. He is currently investigating modified peptides for biomolecular recognition and selfassembly.
Jan van Hest was born in 1968. After completing his MSc in polymer chemistry in 1991 he obtained his PhD in 1996 at Eindhoven University with Prof. Dr. Bert Meijer. Next he worked

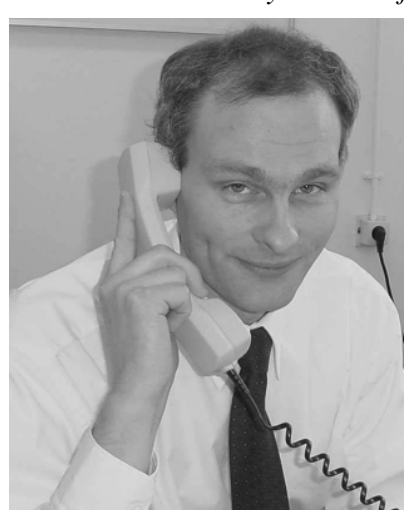
with Prof. Dr. D.A. Tirrell, at the University of Massachusetts in Amherst investigating protein engineering for the preparation of materials. In 1997 he joined DSM company to work on controlled radical polymerization and integration of expertise from life sciences and materials. In 2000 he became full professor at Nijmegen University to set up a group in bio-organic chemistry. 
their interaction with membranes. This could lead eventually to the discovery of compounds with improved therapeutic properties, which can be used as potent or broad-spectrum antibiotics.

These often artificial model peptides can be divided into two types. The first class is comprised of peptides with a linear stretch of hydrophobic residues coupled to a number of polar amino acids that constitute the head group of the peptide amphiphile. The second class consists of structures with alternating polar and apolar residues. It will not be surprising that the properties and modes of interaction with membranes of these two types of amphiphiles differ considerably.

Examples of amphiphilic peptides of the first class are rather limited. Vankann et al. ${ }^{5}$ have investigated how amphiphilic peptides like $\mathrm{Leu}_{12}-\mathrm{Glu}_{3}, \mathrm{Leu}_{8}-\mathrm{Lys}_{5}-\mathrm{Tyr}$ and Fmoc-Leu ${ }_{8}-\mathrm{Lys}_{5}-\mathrm{Tyr}$ behave at the air-water interface and how these peptides integrate into a lipid bilayer. It was found that these compounds, once spread at the air-water interface, exhibited an $\alpha$-helix fold. Upon compression the molecules 'stood up', by lifting the apolar oligoleucine tail out of the water layer, and transformed into extended $\beta$-sheets, which probably provide improved intermolecular interactions for these compounds. Incorporated into liposomes these peptides all displayed small or non-residual $\alpha$ helical content compared to when in solution. This is probably due to the fact that the leucine chains prefer to adopt conformations which correspond best to the length of the lipid bilayer. For the short peptides it was necessary that the leucine fragment was stretched to match the amphiphiles that constitute the bilayer, thereby adopting a $\beta$-sheet conformation. This exemplifies that the fold of a peptide is not only determined by the peptide sequence, but also by its environment.

Zhang and co-workers ${ }^{6}$ have studied both cationic and anionic peptide amphiphiles. These peptides were designed to mimic the properties of polymeric and lipid surfactant molecules. The head group of the peptide amphiphiles was composed of either one or two basic amino acids, like lysine and histidine, or one or two aspartic acids. The hydrophobic tail consisted of six identical hydrophobic amino acids, alanine, valine or leucine in order of increased size of the side chain. Both the cationic and anionic amphiphiles self-assembled into tubular morphologies. Interestingly, the folding of the anionic peptide amphiphiles in the aggregates did not seem to resemble either $\beta$-sheet or $\alpha$-helix as often found in these types of structures, but were proposed to display an unusual chirality of a yet unknown nature. For the cationic systems above the $\mathrm{p} I$ of the head groups the tubes collapsed into membraneous sheets, no longer producing well defined nanostructures. The anionic systems have only been studied at neutral $\mathrm{pH}$, at which they possess a charged head group.

Amphiphilic peptides comprised of alternating hydrophobic and hydrophilic moieties have recently been studied extensively.
Rapaport et al. ${ }^{7}$ have investigated the properties of Pro-Glu-(PheGlu $)_{n}$-Pro ( $n=4,5$ or 7$)$ monolayers at the air-water interface. The alternating hydrophobic phenylalanines and the hydrophilic glutamic acid residues caused the peptide chains to orient parallel to the water surface. Grazing-incidence X-ray diffraction (GIXD) gave evidence of the formation of $\beta$-sheet structures between the individual peptide amphiphiles, as is shown schematically in Figs. $1 \mathrm{~b}$ and $\mathrm{c}$. From the longer peptides the smallest crystalline domains were obtained, which could arise from defects in the stacking of the sheets, in part due to an increased flexibility of the longer chains. It is noteworthy that the terminal prolines turned out to be crucial in obtaining highly ordered structures, suggesting that the selfassembly process could be designed by alterations in the peptide sequence. Without the prolines less ordered structures were obtained like those depicted schematically in Fig. 1a.

Similarly, Powers et al. ${ }^{8}$ have investigated two peptides of 14 and 18 residues respectively (Fig. 2). Both have a D-Pro-Gly dyad

$$
\begin{aligned}
& \text { D-Pro- } \mathrm{Val}-\mathrm{Glu}-\mathrm{Nle}-\mathrm{Glu}-\mathrm{Cys}(\mathrm{DMBHDY})-\mathrm{Glu}-\mathrm{H} \\
& \mathrm{Gly}-\mathrm{Val}-\mathrm{Glu}-\mathrm{Nle}-\mathrm{Glu}-\mathrm{Nle}-\mathrm{Glu}-\mathrm{Nle}-\mathrm{Glu}-\mathrm{NH}_{2} \\
& \text { D-Pro-Val-Glu}-\mathrm{Nle}-\mathrm{Glu}-\mathrm{Nle}-\mathrm{Glu}-\mathrm{Cys}(\mathrm{DMBHDY})-\mathrm{Glu}-\mathrm{H}
\end{aligned}
$$

Fig. 2 14- and 18-residue peptides both having a D-Pro-Gly sequence in the middle of alternating hydrophilic $(\mathrm{Glu})_{4}$, and hydrophobic (Val, norleucine (Nle), labeled Cys) residues.

in the middle of two sequences that consist of alternating hydrophobic and hydrophilic amino acids. While D-Pro-Gly favours a $\beta$-turn and the alternating sequences are prone to $\beta$-sheet formation, it was likely that $\beta$-hairpin structures at the air-water interface would be formed. Monolayers of the peptide amphiphiles were transferred to freshly cleaved mica to afford single layer Langmuir-Blodgett films. These layers were examined, using atomic force microscopy, which yielded images of crystalline domains and substructures that directly correlate with dimensions of the peptide amphiphiles, in agreement with the proposed formation of laterally stacked $\beta$-hairpins, as can be seen in Fig. 3.

The above mentioned ideas were elaborated by $\mathrm{Xu}$ et al. ${ }^{9}$ who prepared small proteins designed to form six $\beta$-strands, each one consisting of seven alternating polar and non-polar residues, which were connected by four amino acids to induce reverse turns. In this case $\beta$-sheet monolayers were formed. It was furthermore concluded that for such larger designed sequences the primary sequence can be less specific, allowing a wide variety of amino acid

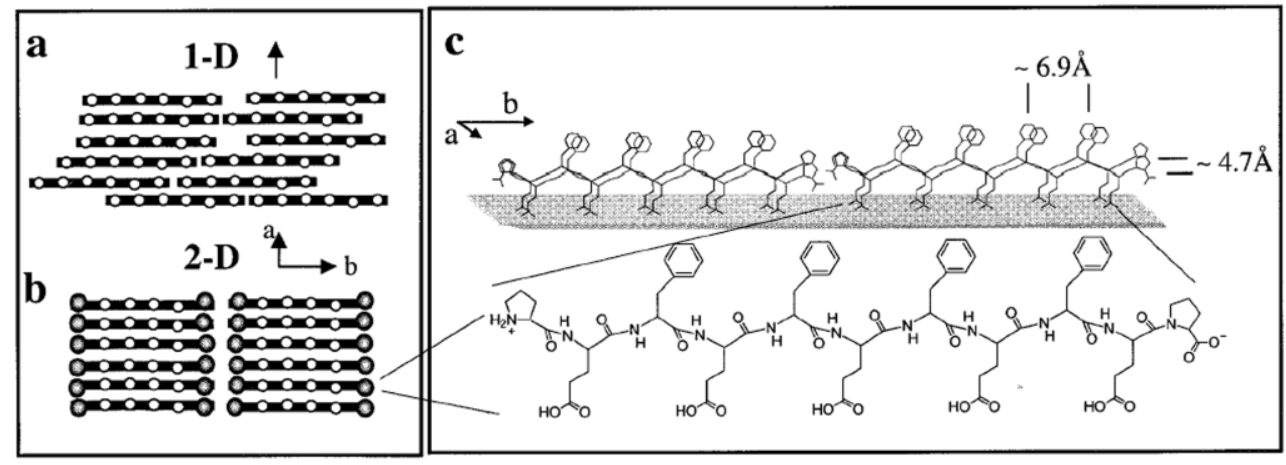

Fig. 1 Schematic diagrams of $\beta$-strand assemblies at the air-water interface (rods and open dots represent peptide backbones and hydrophobic amino acids, respectively). View down the normal to the $\beta$-sheet of (a) one-dimensional order and (b) two-dimensional order induced by distinct chain termini. (c)

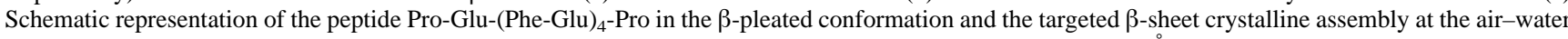
interface. An estimate of the area per molecule can be obtained using the repeat distances of $\sim 4.7$ and $\sim 6.9 \AA$ that have been observed previously in crystalline $\beta$-sheet structures (e.g. $4.7 * 6.9 * 5.5=178 \AA^{2}$ for the 11 residue peptide). Reprinted with permission from (ref. 7). Copyright 2000 American Chemical Society. 

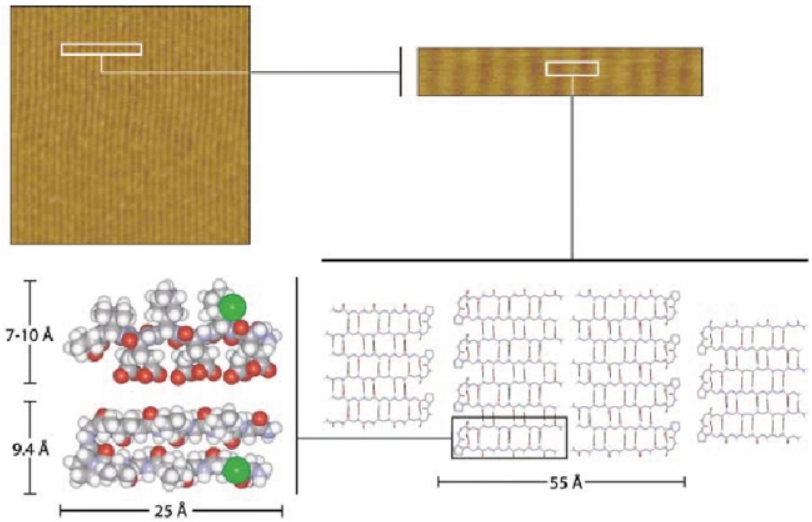

Fig. 3 Molecular model for the assembly of a 14-residue peptide investigated by Powers et al. An AFM image of an LB monolayer of a 14-residue peptide is shown in the top left. A white box encloses a small section of the scan area, which is expanded in the top right. Another white box in the expansion encloses a ridge with two flanking half-ridges. A molecular model for the assembly in the enclosed area is shown in the bottom right. The central ridge corresponds to the two central columns of $\beta$ hairpins, which interact with each other through their polar termini. The flanking half-ridges correspond to the two flanking columns of $\beta$-hairpins, which interact with the central column through turn-turn recognition. The ridge period expected from this model is $55 \AA$ : $25.0 \AA$ for each hairpin, $2 \AA$ for the gap at the termini-to-termini interface (a typical distance for hydrogen bonds), and $3 \AA$ for the gap at the turn-to-turn interface (a typical distance for van der Waals interactions). The panel in the bottom left shows a top view (lower part of panel) and a side view (upper part) of a single hairpin. The hairpins length is $25 \AA$ and its width is $9.4 \AA$ (see top view), while its height can vary from 7 to $10 \AA$ depending on the side chains' conformations (see side view). The green spheres represent the DMBDY fluorophore. Reprinted with permission from (ref. 8). Copyright 2002 Wiley-VCH.

combinations to be assembled into similar structures, as long as they contain stretches of alternating hydrophobic and hydrophilic residues. Fig. 4 shows molecular models of the postulated structures that were observed.

Amphiphilic peptides with alternating polar and apolar residues have not only been used to study assembly at the air-water interface or in liposomes. Schneider et al. ${ }^{10}$ have designed an all-amino acid amphiphile for aggregation into solution, leading to hydrogel formation. A $\beta$-hairpin was constructed in a similar fashion as described by Powers et al. by introduction of a $\beta$-turn stabilizing DPro-L-Pro dyad in the middle of eight repeats of Val-Lys. Under basic conditions the $\beta$-hairpin conformation was readily adopted, leading to one face of the hairpin lined with hydrophobic valine moieties and the other face with hydrophilic lysines. The resulting peptide amphiphile gave rise to an intermolecular assembly into stable hydrogels. Lowering the $\mathrm{pH}$ introduced cationic charges onto the lysine side chains and subsequent repulsion led to disappearance of the hydrogel properties. This behaviour proved to be fully reversible, resulting in a stimulus responsive material.

Finally, Epand et al. ${ }^{11}$ compared the remarkably different properties of two analogous alternating peptides: Ac-(LeuLysLysLeu $)_{5}$-NHEt and Ac-(LysLeu) ${ }_{10}$-NHEt. First of all Ac-(LeuLysLysLeu $)_{5}$-NHEt formed an $\alpha$-helix in the presence of negatively charged lipids, while the other peptide adopted a $\beta$-sheetlike structure under all conditions studied. Moreover, the lytic activity of Ac-(LeuLysLysLeu) ${ }_{5}$-NHEt towards zwitterionic liposomes was found to be significantly higher than that of Ac(LysLeu $)_{10}$-NHEt. However, these activities do not correlate with their haemolytic behaviour or antimicrobial activity, suggesting more complex mechanisms to be involved in these situations.

Within the collection of all-amino acid amphiphilic compounds, a distinct group of alternating-residue peptides is constituted by cyclic peptides, as developed by the group of Ghadiri. ${ }^{12}$ It was found that cyclic peptides with an even number of alternating Dand L-amino acids could adopt flat ring-shaped structures, with the amide bonds perpendicular to the plane of the ring. Within an
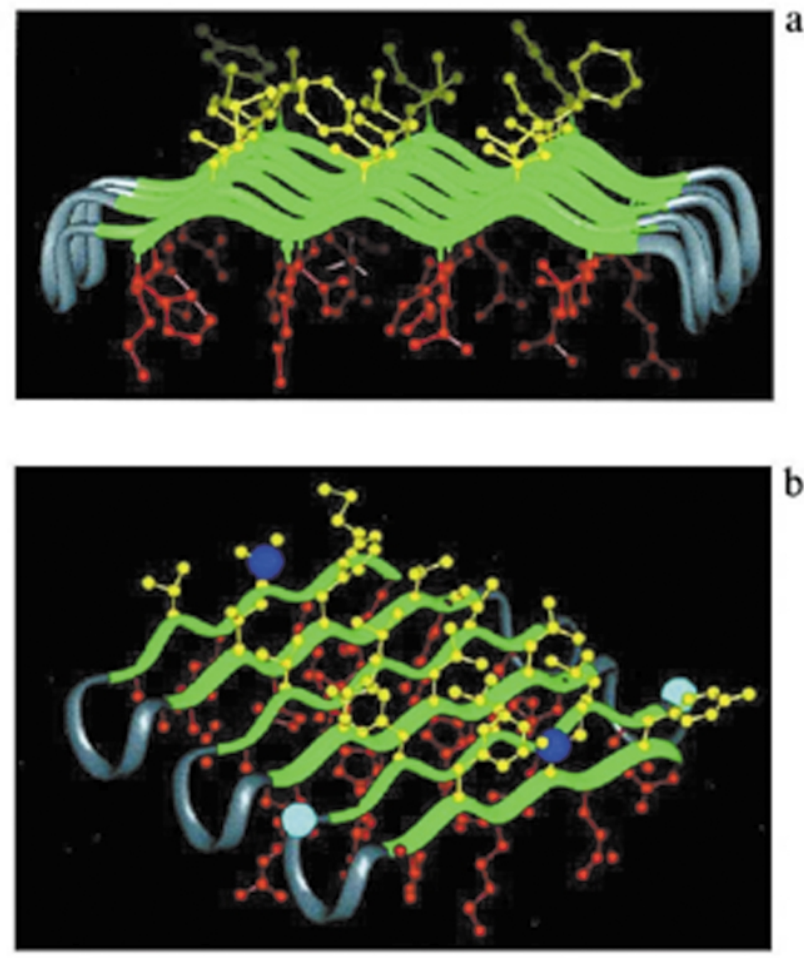

Fig. 4 (a) Molecular model of the $\beta$-sheet protein studied by Xu et al. at the air-water interface: The model shows six antiparallel $\beta$-strands. Each strand contains seven residues - four polar (red) and three non-polar (yellow). The modelled conformation shows a facial amphiphile with a hydrophobic face (toward air) and a hydrophilic face (toward water), thereby facilitating formation of a $\beta$-sheet monolayer at the air-water interface. (b) Same model from a different angle. Measurements indicate the length and width of the $\beta$ sheet. The length of the $\beta$-strands is shown from the $\alpha$-carbon of the residue (Asp-12) preceding the second strand to the $\alpha$-carbon of the residue (Asp20) after the second strand. These $\alpha$-carbons are shown as turquoise balls. The distance between them is $27.2 \AA$. The width of the $\beta$-sheet is shown as the distance from the $\beta$-carbon of the middle residue on the first strand (Ile$5)$ to the $\beta$-carbon of the middle residue of the last strand (Val-60). These atoms are shown as blue balls. This distance is $23.6 \AA$. The area of the $\beta$ sheet is thus $27.2 \AA \times 23.6 \AA=642 \AA^{2}$. This area corresponds to the distance between the turquoise balls multiplied by the distance between the blue balls. This area does not include the polar turns, which are modelled as projecting down into aqueous solvent, nor does it include the area between proteins in the overall structure of the self-assembled monolayer. Reprinted with permission from (ref. 9). Copyright 2001 National Academy of Sciences, USA

environment that promotes hydrogen bond interactions, these rings could self-assemble into stacks leading to the formation of $\beta$-sheetlike tubular structures, as is shown in Fig. 5. With a hydrophobic exterior and a hydrophilic interior these architectures could insert into bilayer membranes introducing pores (Fig. 6). Varying the number of amino acid residues and, hence, the ring size, modulated the porosity, as the smaller 8-residue rings only transport small ions while the larger 10-membered rings could also transport compounds like glucose and glutamic acid. The membrane targeting activity of these systems has been exploited in the development of new antibacterial agents. ${ }^{13}$

\section{Lipidated peptides: single alkyl chains}

The second category of peptide amphiphiles discussed in this review is constituted by hydrophilic amino acid sequences coupled to hydrophobic alkyl chains. In nature lipidated proteins such as members of the Src (tyrosine kinases) and Ras (guanine nucleotide binding proteins) families play important roles controlling biological signal transduction pathways. ${ }^{14}$ The lipid groups, a diversity of alkyl chains, are believed to be involved in protein-protein and protein-lipid interactions and serve as anchors to biomembranes. In 

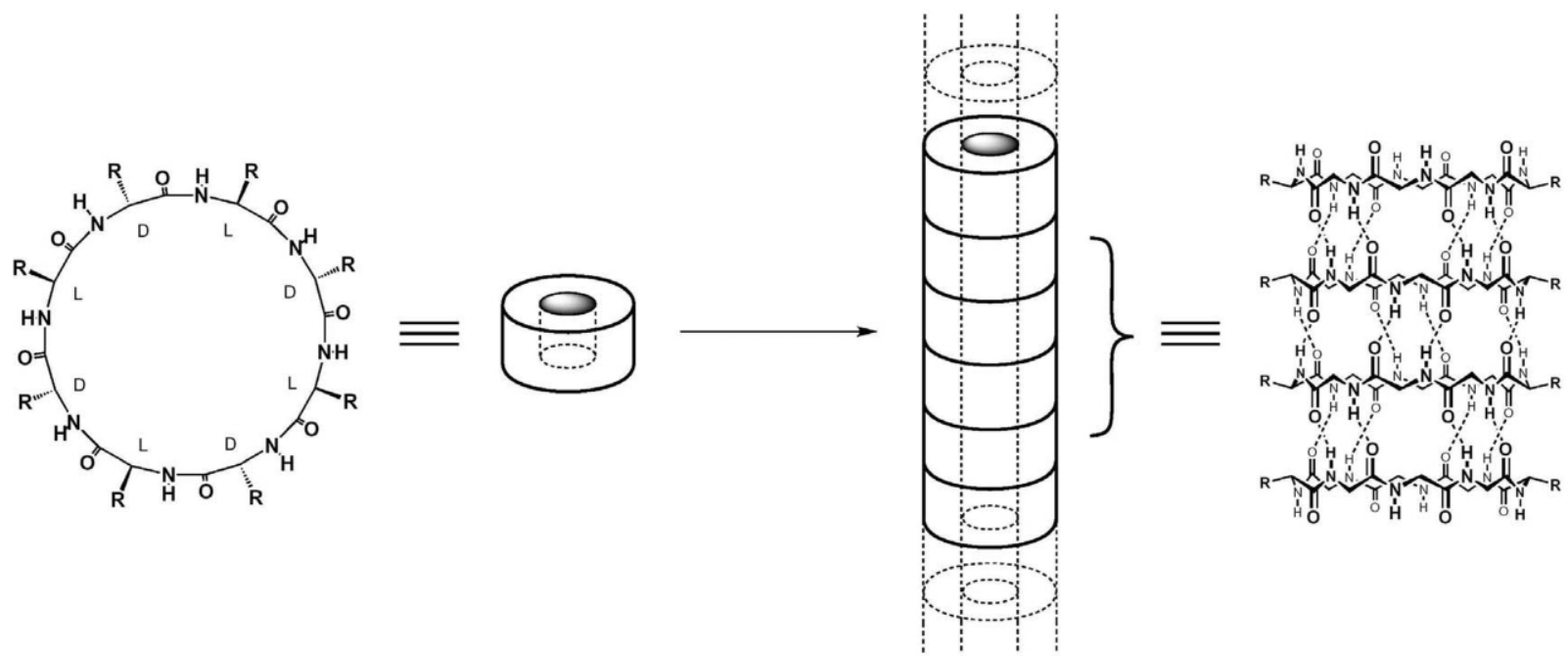

Fig. 5 Schematic diagram of nano-tube assembly from cyclic D, L-peptides. For clarity, most of the peptide side-chains have been omitted. Reprinted with permission from (ref. 12). Copyright 2001 Wiley-VCH.

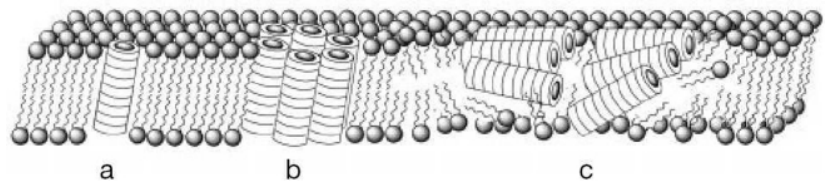

Fig. 6 Cyclic D, L- $\alpha$-peptide nano-tubes can display sequence-dependen modes of membrane permeation: a) intramolecular pore; b) barrel stave; and c) carpet-like (cyclic peptides are depicted as ring structures). Reprinted with permission from (ref. 13). Copyright 2001 Nature Publishing Group.

addition, $\mathrm{N}$-terminally alkylated peptides are also commonly found in nature, such as the marine siderophores, ${ }^{15}$ which are known to bind iron (Fig. 7). Intriguingly, these amphiphiles self-assemble

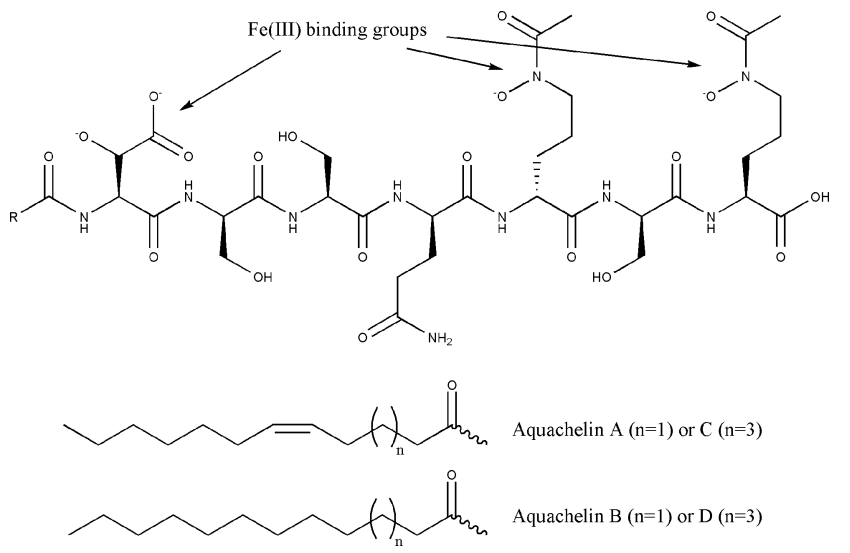

Fig. 7 The structure of siderophores: aquachelins.

into micelles, which transform into vesicles in the presence of $\mathrm{Fe}$ (III) ions. Another example are peptaibols, membrane active metabolites of fungal origin, constructed from peptides $\mathrm{N}$ terminally modified with lipophilic octanoyl and decanoyl moieties, which are now under investigation for their possible antitumour activity. ${ }^{16}$ In this category of naturally occurring lipopeptides a special group worth mentioning are those with cyclic peptide head groups such as the surfactins. ${ }^{17}$ These bacterial cyclic peptide amphiphiles are well known for their exceptional surfactant power, capable of drastically lowering the surface tension of water at low concentrations. Investigations into their properties and biochemical actions have shown that these biosurfactants also possess antibacterial, antiviral, anti-tumoural and even hypocholesterolemic properties, and might possibly lead to a new class of therapeutics.

The most widely studied class of synthetic peptide amphiphiles consists of compounds that incorporate one or two lipid alkyl tails, usually, by acylation of the N-terminus. The groups of Fields and Tirrell have investigated peptides connected to monoalkyl hydrocarbon chains. ${ }^{18,19}$ They have shown that $\mathrm{N}$-acylation of a peptide with a hydrophobic moiety can be used to induce protein-like structures. A 16-residue peptide, derived from a model peptide for $\alpha$-helices that dimerizes to form a distinct structure at a chain length of 23 amino acid residues, did not form any distinct structure in solution. However, once connected to a $\mathrm{C}_{6}$ or $\mathrm{C}_{16}$ alkyl chain an $\alpha$ helical structure was adopted, as was evidenced by CD and NMR spectroscopy (see Table 1). The longer $\mathrm{C}_{16}$ modified peptide had a

Table $1 \mathrm{Tm}$ values for $\alpha$-helix or triple helix $\leftrightarrow$ coil transitions

\begin{tabular}{|c|c|c|}
\hline \# & Peptide or peptide amphiphile ${ }^{a}$ & $\begin{array}{l}T \mathrm{~m} \\
\left({ }^{\circ} \mathrm{C}\right)\end{array}$ \\
\hline 1 & Lys-Ala-[Glu-Ile-Glu-Ala-Leu-Lys-Ala] $]_{2}-\mathrm{NH}_{2}$ & $\mathrm{NH}^{b}$ \\
\hline 2 & $\mathrm{C}_{6}$-Lys-Ala-[Glu-Ile-Glu-Ala-Leu-Lys-Ala $]_{2}-\mathrm{NH}_{2}$ & 46.0 \\
\hline 3 & $\mathrm{C}_{16}$-Lys-Ala-[Glu-Ile-Glu-Ala-Leu-Lys-Ala $]_{2}-\mathrm{NH}_{2}$ & 65.0 \\
\hline 4 & $\left(\mathrm{C}_{12}\right)_{2}$-Glu-C ${ }_{2}$-Lys-Ala-[Glu-Ile-Glu-Ala-Leu-Lys-Ala $]_{2}-\mathrm{NH}_{2}$ & 59.0 \\
\hline 5 & $(\text { Gly-Pro-Hyp })_{4}-[\mathrm{IV}-\mathrm{H} 1]-(\text { Gly-Pro-Hyp })_{4}-\mathrm{NH}_{2}$ & 35.6 \\
\hline 6 & $\mathrm{C}_{6}-(\text { Gly-Pro-Hyp })_{4}-[\mathrm{IV}-\mathrm{H} 1]-(\mathrm{Gly}-\mathrm{Pro}-\mathrm{Hyp})_{4}-\mathrm{NH}_{2}$ & 42.2 \\
\hline 7 & $\mathrm{C}_{8}-(\text { Gly-Pro-Hyp })_{4}-[\mathrm{IV}-\mathrm{H} 1]-(\text { Gly-Pro-Hyp })_{4}-\mathrm{NH}_{2}$ & 45.6 \\
\hline 8 & $\mathrm{C}_{10^{-}}$(Gly-Pro-Hyp $)_{4}-[\mathrm{IV}-\mathrm{H} 1]-(\text { Gly-Pro-Hyp })_{4}-\mathrm{NH}_{2}$ & 51.3 \\
\hline 9 & $\mathrm{C}_{12}$-(Gly-Pro-Hyp $)_{4}$-[IV-H1]-(Gly-Pro-Hyp $)_{4}-\mathrm{NH}_{2}$ & 55.0 \\
\hline 10 & $\mathrm{C}_{14}$-(Gly-Pro-Hyp $)_{4}-[\mathrm{IV}-\mathrm{H} 1]-(\mathrm{Gly}-\mathrm{Pro}-\mathrm{Hyp})_{4}-\mathrm{NH}_{2}$ & 63.1 \\
\hline 11 & $\mathrm{C}_{16}-(\text { Gly-Pro-Hyp })_{4}-[\mathrm{IV}-\mathrm{H} 1]-(\mathrm{Gly}-\mathrm{Pro}-\mathrm{Hyp})_{4}-\mathrm{NH}_{2}$ & 69.8 \\
\hline 12 & $\left(\mathrm{C}_{12}\right)_{2}-$ Glu-C ${ }_{2}-(\text { Gly-Pro-Hyp })_{4}-[\mathrm{IV}-\mathrm{H} 1]-(\mathrm{Gly}-\mathrm{Pro}-\mathrm{Hyp})_{4}-\mathrm{NH}_{2}$ & 71.2 \\
\hline
\end{tabular}

higher thermal stability compared with the $\mathrm{C}_{6}$ analogue, with $\alpha$ helix to coil transitions of 65 and $46{ }^{\circ} \mathrm{C}$ respectively, which could be correlated to the extent of aggregation. This stabilization was also shown with a 39-residue peptide (Table 1), derived from type IV collagen which is prone to form triple-helix assemblies. Remarkably, $\mathrm{N}$-acylation with hexanoic acid already improved the stability of the triple helices, and with increasing alkyl chain lengths even higher thermal stability of the structures was obtained. This enhancement may partly be due to the observed increase of the aggregate size. It was also found that simple alkylation of peptides like $(\mathrm{Gly})_{n}(n=1-5)$ with a $\mathrm{C}_{18}$ alkyl chain resulted in the formation of helical structures, which the peptides would not form otherwise. The stabilizing effect on peptide secondary structure by the attachment of hydrophobic alkyl chains to peptides seems to be a more general phenomenon, and might be utilized for studying the mechanisms of peptide folding and for the formation of more complex protein-like structures and peptide-based assemblies. 
Hartgerink et al..$^{20}$ exploited the typical self-assembly of single alkyl chain containing peptide amphiphiles for the preparation of tailor-made nanostructured composite materials suited for controlled biomineralization. The designed peptide was built up out of five different regions, each with its specific functionality, as depicted in Fig. 8: 1) The alkyl chain was incorporated for

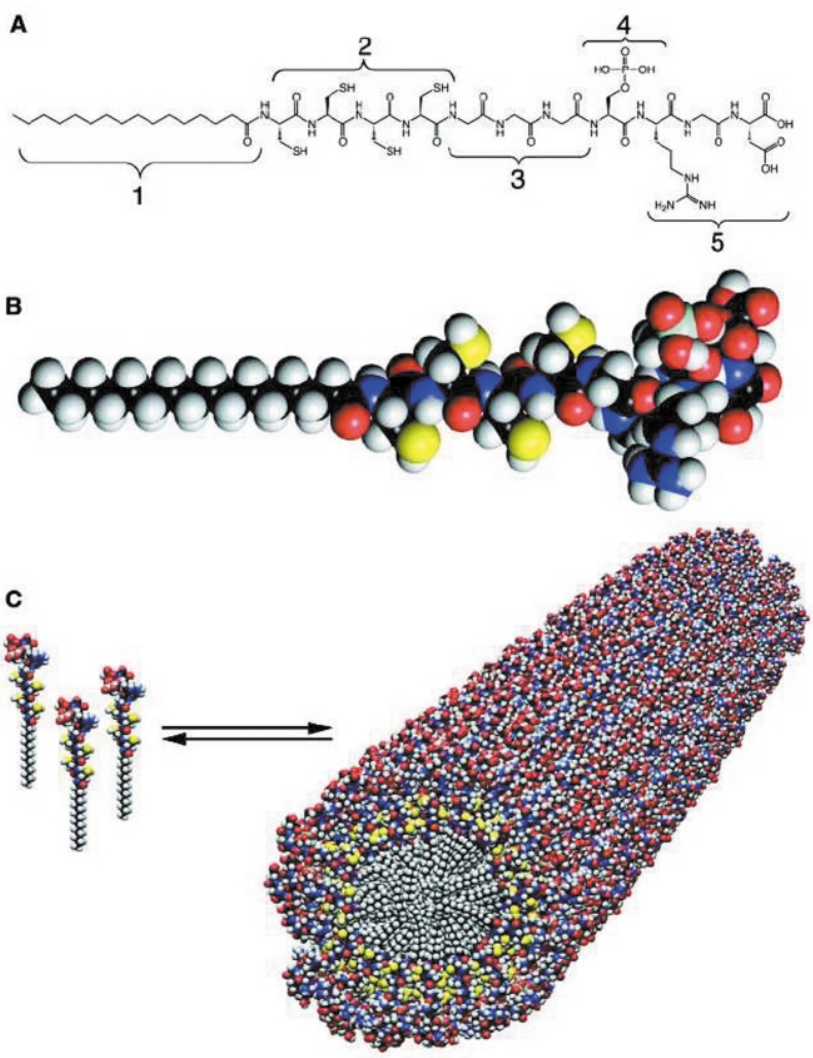

Fig. 8 A) Chemical structure of Hartgerink's peptide amphiphile, highlighting five key structural features (see text). B) Molecular model of the peptide amphiphile, showing its conical shape. C) Schematic showing the self-assembly of the amphiphiles into a cylindrical micelle. Reprinted with permission from (ref. 20). Copyright 2001 AAAS.

conveying hydrophobic character to the molecule, promoting selfassembly. 2) The cysteines were introduced to be able to stabilize the aggregates, once they were formed, by means of polymerization. 3) The glycines inferred some flexibility between the crosslinked area and the hydrophilic head group. 4) The phosphorylated serine could interact strongly with calcium ions to direct mineralization and finally 5) an RGD sequence was attached as a cell adhesion ligand. This design allowed the fibres to be susceptible to $\mathrm{pH}$-dependent cross-linking. At a $\mathrm{pH}$ of 8 , and with all cysteines reduced, the peptide amphiphiles were highly soluble. Upon acidification the compound became insoluble and formed a network of fibres. This process was found to be reversible. The fibres could be stabilized by formation of disulfide bonds through oxidation, after which mineralization of hydroxyapatite was directed by the obtained structure, forming a composite material with an alignment that is also observed between collagen fibrils and hydroxyapatite in bone. This highly dynamic amphiphilic peptide system which may be also covalently captured, might prove to be an ideal scaffold for a plethora of biomineralization and tissue engineering applications.

Much research has focused on the attachment of n-alkyl chains to peptides. Alternatively, the group of Peterson has reported the synthesis of peptides capped with $N$-cholesterylglycine (Fig. 9), inspired by protein toxins such as shiga toxin and cholera toxin. ${ }^{21}$ The lipophilic cholesteryl moiety anchors the peptides stably into membranes of living cells, exposing the peptides as receptors onto the membrane surface. Binding of cognate proteins to these membrane-anchored peptides triggers chlathrin-mediated endocy-

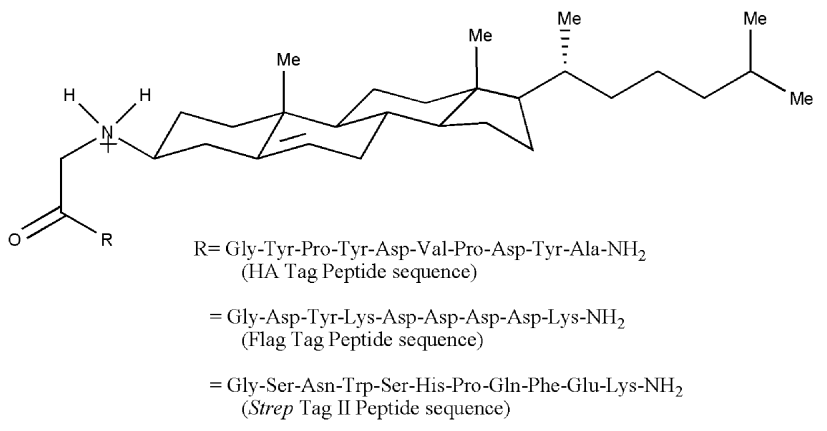

Fig. 9 Structures of non-natural receptors based on $N$-(3ß)-cholesterylglycine-capped peptides.

tosis of the ligand-protein complex. It is suggested that this strategy might enable the delivery of lethal proteins into tumour cells and could also be applicable for the delivery of other biomacromolecules.

Huo et al. have incorporated $N$-acylated peptide lipids into a Langmuir monolayer to form receptors for both sugars ${ }^{22}$ and metal ions. ${ }^{23}$ The dynamic character of such monolayers was exploited to create dynamic combinatorial libraries of receptors that displayed substrate specificity. Langmuir monolayers made of peptide libraries (stearoyl-modified tri- and hexapeptides, see Table 2)

Table 2 The structures and building blocks for the synthesis of the peptide libraries: $\mathrm{C}_{17} \mathrm{H}_{35} \mathrm{C}(\mathrm{O})-\mathrm{Xxx}^{1}-\mathrm{Xxx}^{2}-\mathrm{Xxx}^{3}-\mathrm{OH}$ or $\mathrm{C}_{17} \mathrm{H}_{35} \mathrm{C}(\mathrm{O})$-Gly-Gly$\mathrm{Xxx}^{1}-\mathrm{Xxx}^{2}-\mathrm{Xxx}^{3}-\mathrm{Gly}-\mathrm{OH}$

\begin{tabular}{llr}
\hline Library & $\mathrm{Xxx}^{1}, \mathrm{Xxx}^{2}, \mathrm{Xxx}^{3}$ & \# of components \\
\hline LIB & Gly, Glu, Ser, His, Thr & 250 \\
SUB1 & Gly, Ser, Tyr & 54 \\
SUB2 & Gly, Glu, Tyr & 54 \\
SUB3 & Glu, Ser, His & 54 \\
\hline
\end{tabular}

were constructed and their surface behaviour was studied on an aqueous subphase, containing different solutes. The authors claimed that the peptide lipids self-assemble at the air-water interface to form protein-like supramolecular structures capable of selectively recognizing specific ligands, as is depicted schematically in Fig. 10. In a second study ${ }^{23}$ the ability of similar peptide

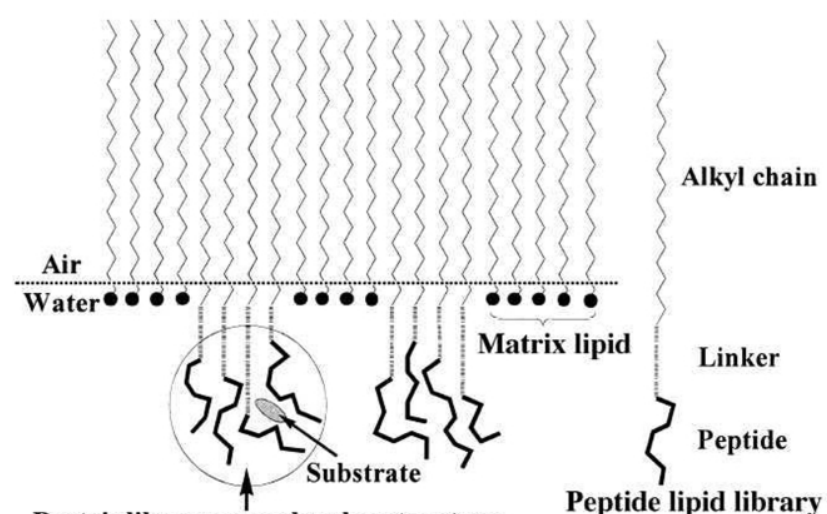

Proteinlike supramolecular structure

Peptide lipid library

Fig. 10 An illustration of the self-assembly of peptide-lipid library components at the air-water interface to form protein like supramolecular structures. Reprinted with permission from (ref. 22). Copyright $2000 \mathrm{Wiley-}$ $\mathrm{VCH}$.

lipids to form complexes with metal ions like $\mathrm{Cu}^{2+}$ and $\mathrm{Zn}^{2+}$ was investigated. In this case binding performance was not affected by going from single peptide lipids to a mixture. However, hard metal ions, like $\mathrm{K}^{+}$and $\mathrm{Mg}^{2+}$, clearly exhibited different binding activity than borderline and soft ions. Furthermore, based on fluorescent probe studies, differences were found between $\mathrm{Cu}^{2+}$ and $\mathrm{Zn}^{2+}$ containing subphases. The authors suggest that these differences 
are to be assigned to a different mode of binding of the ions, leading to altered folding and thus assembly of the peptides in the monolayer. Both studies might well prove to be a starting point of a novel approach in the design of receptor molecules, coined combinatorial surface chemistry, to yield unprecedented proteinlike supramolecular structures.

These ideas have recently been extended into three dimensions, with the preparation of liposomes with glucose binding sites by means of molecular imprinting. ${ }^{24} \mathrm{~A}$ mixture of three amphiphilic dipeptides (Glu-Glu, Asn-Glu and Gln-Glu, all esterified with hexadecanol at both carboxylic acids of the C-terminal glutamic acid) were prepared and incorporated into dipalmitoylphosphatidylcholine (DPPC) liposomes. The binding sites were created by mixing the liposomes with glucose above the liposomal phase transition temperature and subsequently freezing in the obtained structures by lowering the temperature below the transition point. Surface plasmon resonance measurements revealed that only imprinted liposomes containing all three types of peptide amphiphiles were able to bind glucose. It will be interesting to see whether this technique might also be employed for the recognition of more complicated structures like oligopeptides, proteins and cell-surfaces. The resulting materials might be employed to $e . g$. create novel sensing devices, biomaterials or drug delivery systems. ${ }^{25}$

\section{Lipidated peptides: multiple alkyl chains}

With the above mentioned doubly alkylated dipeptides of Seong et $a l .{ }^{24}$ we arrive at a second class of lipidated peptides, that has been pioneered by Kunitake ${ }^{26}$ and Ringsdorf 27,28 The introduction of double or triple chain alkyl moieties to the $\mathrm{N}$ - or $\mathrm{C}$ terminus of peptides resulted in amphiphiles with increased hydrophobicity. Kunitake has employed this type of peptide amphiphiles for interfacial molecular recognition purposes. Dipeptides provided with N-terminal double-chain hydrophobic moieties were shown to interact selectively with water-soluble dipeptides at the air-water interface. Fig. 11 shows proposed modes of binding. Key factors for binding are not only the amenability of the host and guests to form hydrogen bonds, but also steric aspects and placement of the amino acid (hydrophobic) side chains were crucial determinants for the formation of non-covalent assemblies. When mixtures of amphi- philes with a different peptide head group were utilized, a redistribution of monolayer components was observed upon interaction with guest molecules. The dynamic nature of the interacting elements allows for an induced-fit mechanism, to create a binding site appropriate for the guest molecule. The advantage of such a flexible system is of course that it is able to adapt to a variety of guest molecules, however, if selectivity is desired and needs to be maintained, a means of capturing the obtained dynamic receptor sites would be required.

An interesting variation has been reported by Neumann et al. ${ }^{27}$ Cysteine and homo-cysteine, of which the side chains were modified with a dialkylated moiety were used for the preparation of vesicles. Treatment of these aggregates with water-soluble carbodiimides induced oligomerization of the amino acids to obtain peptide amphiphiles, as is shown in Fig. 12. Surprisingly, the very low permeability of the amino acid vesicles increased upon polymerization, contrary to what is usually found upon polymerization of vesicles.

Tirrell and Fields ${ }^{29}$ have investigated the construction of biologically active protein-like structures, based on collagen-like peptide amphiphiles (entry 12, Table 1). These structures were prepared in their entirety on the solid phase and were designed to entail four building blocks: two hydrophobic alkyl tails, introduced by esterification of both carboxylic acids of a $\mathrm{N}$-terminal glutamic acid residue, a succinic acid spacer and a collagen model peptide head group incorporating a cell binding sequence. These structures self-assembled in water into highly ordered collagen type II-like triple helical structures. The hydrophobic moiety directed and stabilized the formation of the triple helix. The difference in denaturing temperatures of the peptide structures modified with one or two $\mathrm{C}_{12}$ alkyl chains was about $15-20^{\circ} \mathrm{C}$. However, in order for monolayers of these amphiphiles to be able to serve as a template for cell adhesion it was found that the peptide amphiphiles needed to be placed in a matrix of non-functionalized lipid. Probably, once transferred to a surface the molecular packing plays an important role in cell interactions.

Another functional peptide sequence that has been combined with a double alkyl hydrophobic moiety is the Arg-Gly-Asp (RGD) sequence. This so-called universal recognition site has been shown to mediate the interaction of the extracellular matrix with a variety of proteins involved in endothelial cell binding processes. Yagi $e t$ $a l .{ }^{30}$ have prepared liposomes whose surface is modified with
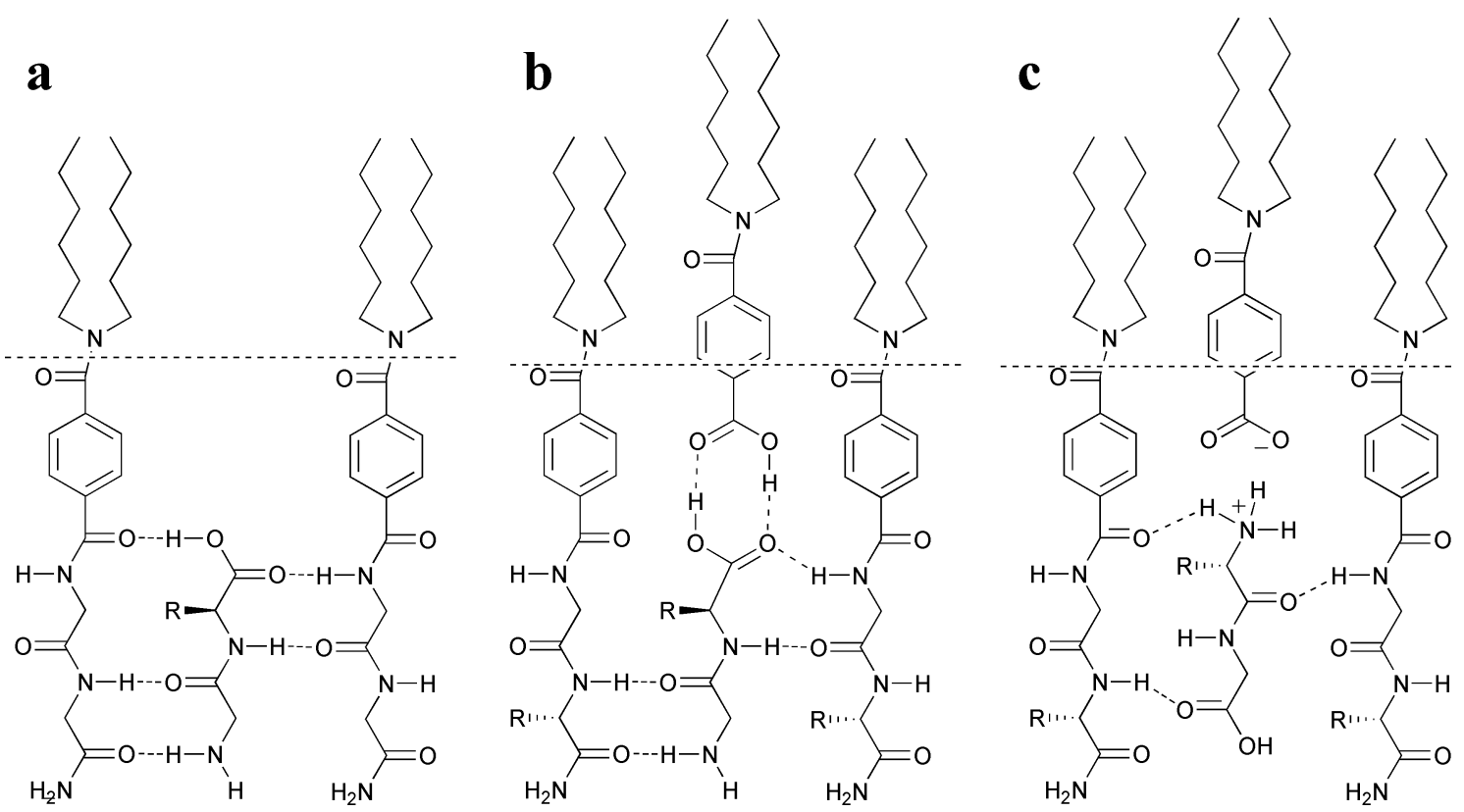

Fig. 11 Schematic representation of binding modes of aqueous peptides to peptide-functionalized monolayers: a) a monolayer of a double-chain oligoglycine amphiphile $\left(2 \mathrm{C}_{18} \mathrm{BGlyGlyNH}_{2}\right)$ with Gly-Xxx by C-terminal insertion; b) a $1: 1$ mixed monolayer of $2 \mathrm{C}_{18} \mathrm{BGlyValNH}_{2} / 2 \mathrm{C}_{18} \mathrm{BCOOH}$ with $\mathrm{Gly}-\mathrm{Xxx}$ by $\mathrm{C}-$ terminal insertion.; c) a 1:1 monolayer of $2 \mathrm{C}_{18} \mathrm{BGlyValNH} \mathrm{H}_{2} / 2 \mathrm{C}_{18} \mathrm{BCOOH}$ with $\mathrm{Xxx}$-Gly by N-terminal insertion. 


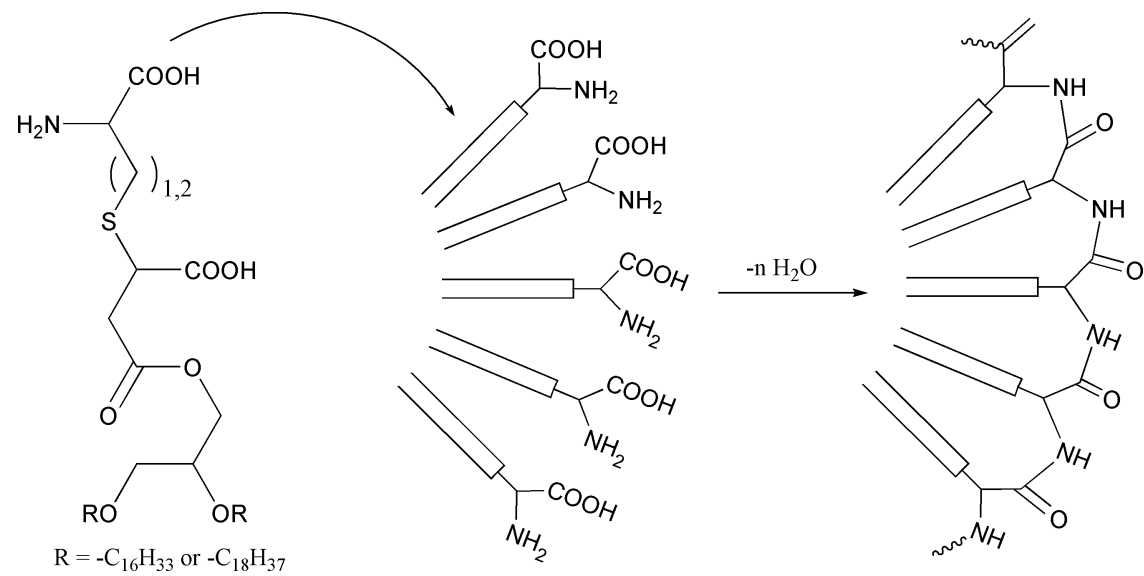

Fig. 12 Amphiphilic amino acids and their condensation polymerization aggregated in bilayers.

peptides containing a five-time repeat of the GRGDS sequence (Fig. 13), as found in the cell adhesion sequence of fibronectin. The
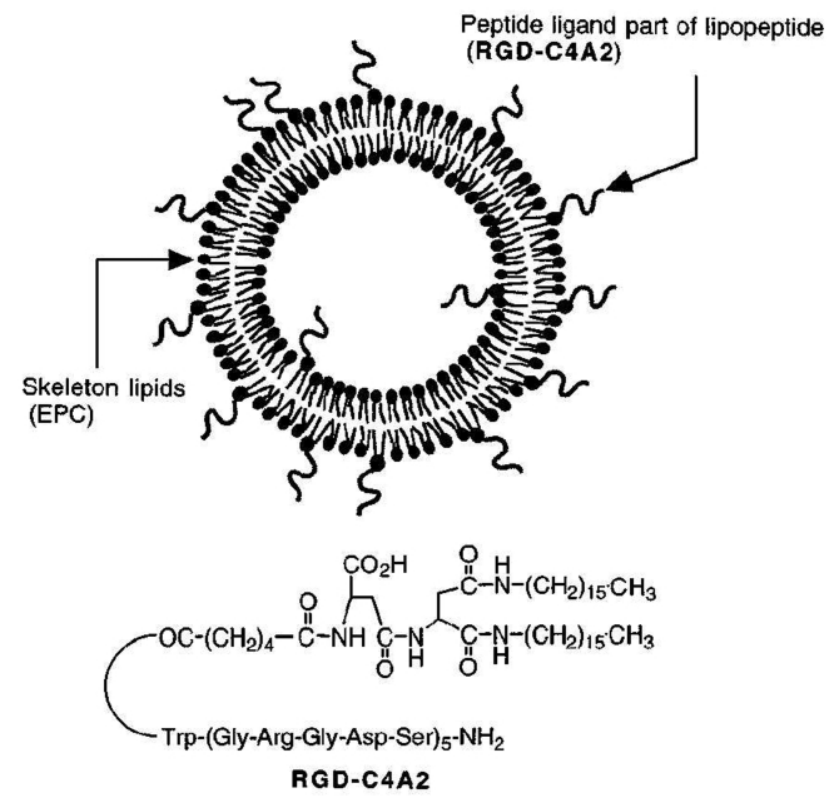

Fig. 13 A lipopeptide that has a five-times repeated GRGDS sequence, which is the same as the cell adhesion sequence of fibronectin.

peptide was lipidated by incorporation at the $\mathrm{N}$-terminus of an aspartic acid residue modified with two $\mathrm{C}_{16}$ alkyl chains. The availability of the peptides on the surface was confirmed using immuno-electron microscopy, employing a specific antibody to the peptide that could be visualized with gold colloids. The liposomes were shown to bind mouse fibroblast cells. The association takes place through interaction of the exposed peptide and the corresponding cell surface receptor.

Most approaches to display RGD-containing peptides immobilize the peptide by covalently linking it through the $\mathrm{N}$ terminus, leaving the carboxy-terminus free. It is a well-known fact, however, that the RGD sequence exists in a conformationally constrained loop in proteins such as fibronectin. It has been demonstrated that cyclic peptides which contain the RGD sequence can display higher affinities than their unconstrained linear counterparts. Pakalns et al. ${ }^{31}$ have shown that the same conformational constraint can be obtained by attaching doubly alkylated glutamic acid derivatives to both the $\mathrm{N}$ - and $\mathrm{C}$-terminus to afford a compound as is depicted in Fig. 14. These peptide amphiphiles were utilized to prepare self-assembled monolayers which could be deposited as Langmuir-Blodgett films on a surface. On these surfaces functionalized with looped RGD amphiphiles, melanoma cells were able to spread in a concentration dependent manner.

A similar approach has been followed to enhance the activity of the RGD sequence towards integrin receptors. Marchi-Artzner et $a l .32$ have attached a cyclized RGD containing pentapeptide to lipid alkyl chains connected through a short ethylene glycol spacer, shown in Fig. 15. A supported membrane containing these amphiphiles selectively adhered to endothelial cells of the human umbilical cord. Moreover, giant vesicles functionalized with cyclic RGD peptides adhered to the same endothelial cells (Fig. 16), a process that could be inhibited by adding the corresponding soluble peptide. This suggests a specific interaction between the bilayer anchored peptide and the integrin receptors of the cells. Recently, in a similar approach the group of Robinson has displayed the NPNArepeat motif from the CS-protein of the Malaria parasite, Plasmodium falciparum, on the surface of immuno-reconstituted influenza virosomes, in structure very similar to liposomes. ${ }^{33}$

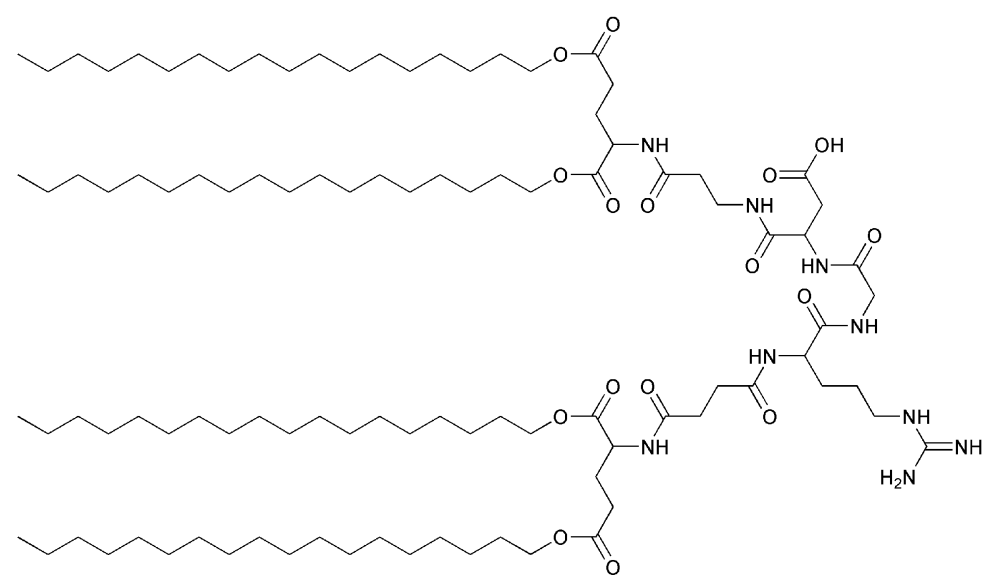

Fig. $14 \mathrm{An} \mathrm{N}$ - and C-terminally lipidated 'looped' RGD peptide. 


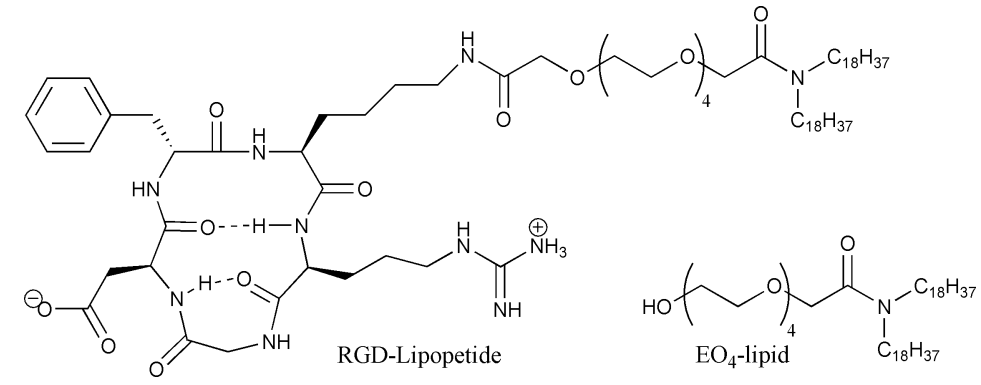

Fig. 15 A cyclic RGD-lipopeptide.

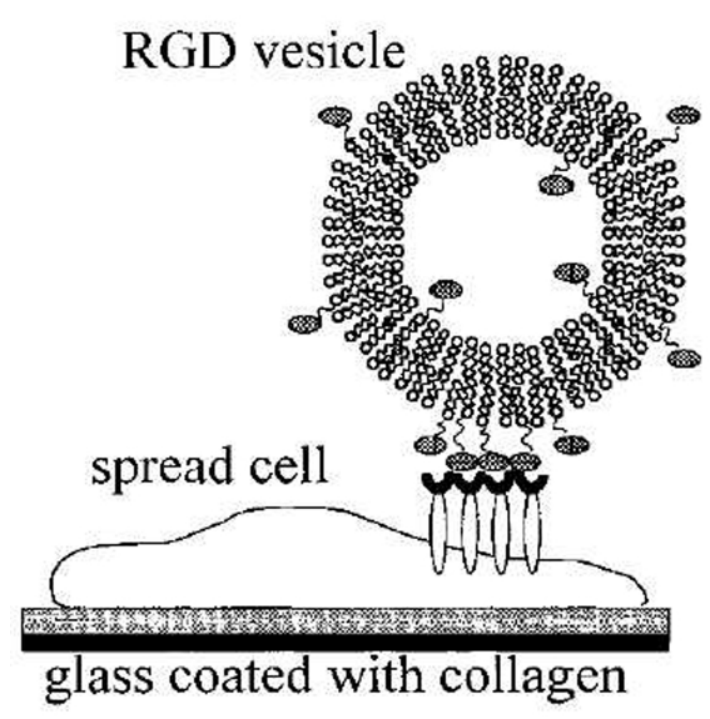

Fig. 16 Schematic view of model system studied endothelial cell adhesion to glass substrate coated by collagen and interaction with a giant vesicle containing the cyclic RGD-lipopeptide. Reprinted with permission from (ref. 32). Copyright 2001 Wiley-VCH.

From the above mentioned examples it is clear that the introduction of hydrophobic double alkyl chains affects the folding and assembly of the peptide parts. In line with recent work of Stupp and co-workers, ${ }^{20}$ Ihara et al. ${ }^{34}$ have shown as early as the mideighties that peptide amphiphiles are able to form molecular assemblies, going from globular structures, to at that time unusual morphologies. Within a few hours, initial globular aggregates of peptide amphiphiles with poly-aspartic acid head groups converted to fibrous aggregates that finally produced twisted ribbon like structures. The authors believe this to be a stepwise process as is shown schematically in Fig. 17. With the renewed attention to peptide amphiphiles and their aggregates it will be interesting to see what factors determine the morphology of the aggregates and whether the outcome can truly be designed. An important question that remains to be answered is how the secondary structure of the peptide influences the aggregation behaviour and vice versa.

Recently, Löwik et al. ${ }^{35}$ have demonstrated that a short peptide can be anchored into liposomes by attaching single $\mathrm{C}_{18}$ alkyl chains to both the $\mathrm{N}$ - and $\mathrm{C}$-terminus. Such peptides were easily prepared using an entirely solid phase strategy, commencing with an aldehyde functionalized resin that was reductively aminated with the appropriate alkyl amine. This generic strategy allows for the easy preparation of amphiphilic peptides regardless of their amino acid sequence. Anchoring such $\mathrm{N}$ - and C-terminally modified peptides into a lipid bilayer had a strong influence on their folding behaviour. To demonstrate the conformational effects of alkylating both $\mathrm{N}$ - and C-termini a sequence derived from the CS protein of the malaria parasite Plasmodium falciparum was chosen, based on the above mentioned work by Robinson et al. ${ }^{33} \mathrm{Within}$ the natural protein this Asn-Pro-Asn-Ala repeat is known to adopt a $\beta$-turn. Both the unmodified peptide in solution and the analogous peptide

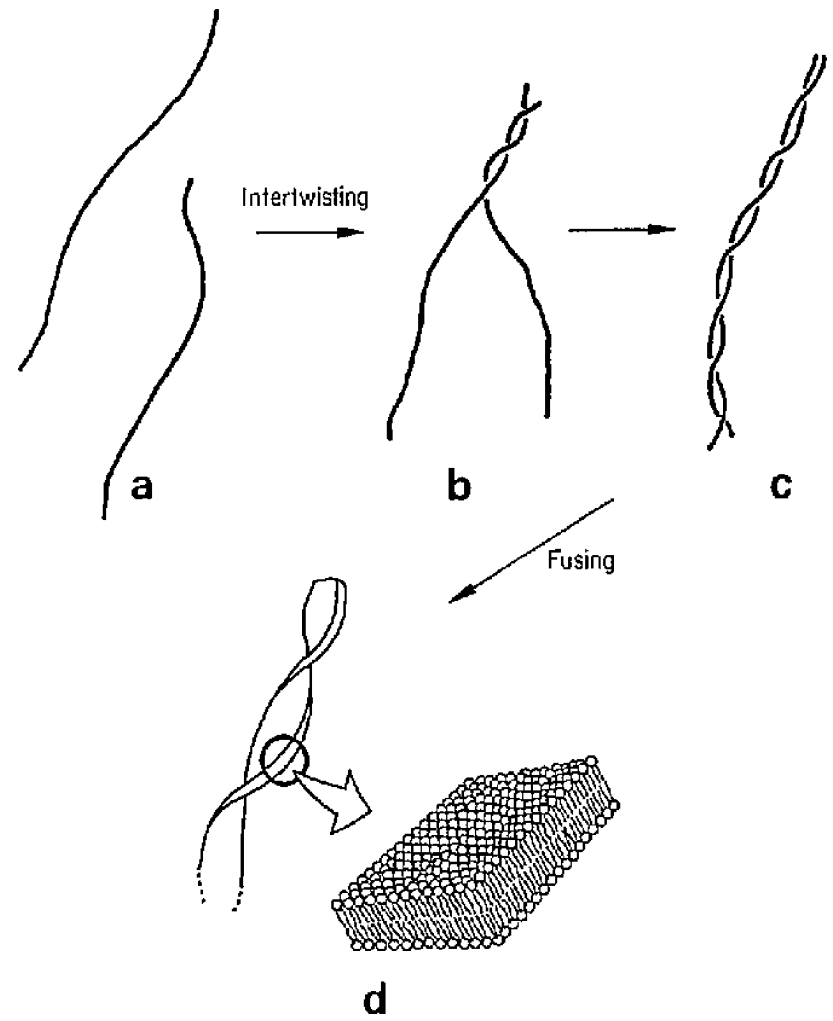

Fig. 17 Schematic illustrations of the morphogenesis of aggregates of polyaspartic acid head group containing amphiphiles. a) untwisted filaments; $b$, c) double-helix; and d) twisted-ribbon and bilayer structures. Reprinted from (ref. 34). Copyright (1986), with permission from Elsevier.

with only one alkyl chain inserted into DSPC liposomes showed random coil folding characteristics. However, when the doubly functionalized peptide was anchored into liposomes the peptide folded into a $\beta$-hairpin, as is shown in Fig. 18. It is proposed that

1 Ac-Gly.AlaAsn Pro-AsnAla:AlaGly·OH

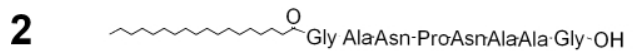

3 3 Gly AlaAsn-ProAsnAlaAla-Gly:N

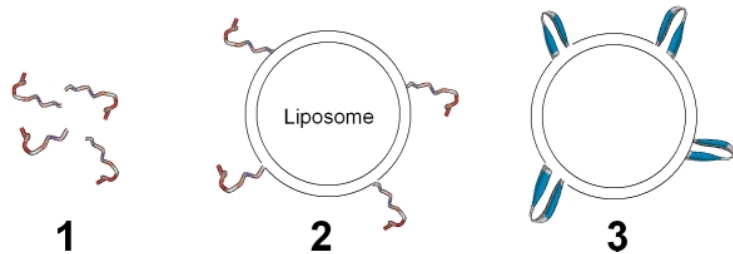

Fig. 18 Stabilization of a $\beta$-hairpin by attachment of terminal alkyl tails.

this simple approach will be a convenient way for stabilizing a variety of peptides into their preferred secondary folds on a lipid bilayer and might well be employed in the presentation of multiple (hairpin) epitopes. 
Aggregation behaviour can be modulated if a charged group is introduced at the end of one of the terminal alkyl chains, as devised by Ariga et al. (Fig. 19). ${ }^{36}$ Now, an ammonium group was the hydrophilic head group of the amphiphilic molecules and the peptide part formed an integral part of the bilayer structure upon aggregation. The peptides assembled into parallel $\beta$-sheets as directed by the position of the amphiphilic components. Antiparallel $\beta$-sheets were also accessible by mixing in another tripeptide with the charged head group on the opposite side, thereby, reversing its direction as directed by the electrostatics. Furthermore, the assembly process was highly influenced by the polarity of the solvents the compounds were dispersed in, as depicted in Fig. 20. Going from water to $\mathrm{CCl}_{4}$ inverted aggregates were observed with different properties due to the position of the charged groups in the bilayers. Interestingly, all supramolecular assemblies had very similar internal structure but displayed pronouncedly different morphologies. In this case the assembly history was a key determining factor in the outcome of the aggregation process.

As an alternative to attaching alkyl chains to either the N- or Cterminus, peptide side chains may also be lipidated. For example, hemagglutinin, a glycoprotein from influenza virus A, contains $S$ palmitoylated cysteines next to its transmembrane region (Fig. 21). The lipid moieties are thought to be important during budding and fusion processes. In view of this Eisele et al. ${ }^{37}$ prepared peptide fragments from hemagglutinin lipidated at the cysteines. They developed a synthetic strategy for this purpose, introducing a new para-phenylacetoxybenzyloxycarbonyl (PAOB) protective group that can be removed under very mild conditions with an enzyme. It was shown that one alkyl group is not sufficient to completely anchor the peptide into a membrane and prevent it from hopping from one liposome to another.

\section{Peptide-based block copolymers}

In the previous paragraphs amphiphile assembly mainly was investigated in relation to biological activity. In some cases, emphasis of research was directed specifically to exploit the aggregation behaviour of amphiphilic peptides as a versatile method for the construction of self-assembled nanometre-sized objects. This application is even more relevant for a special class of peptide amphiphiles, in which both hydrophobic and hydrophilic domains are built up of polymers, polypeptides or even proteins. With the recent interest in nano-scale structures, and the further development of synthetic and supramolecular strategies, peptidebased amphiphilic block copolymers have become available as larger sized building blocks for self-assembled materials. Allpolypeptide based amphiphiles were studied by Conticello et al. based on elastin derived block copolymers. ${ }^{38}$ Elastin like polypeptides such as $[(\mathrm{Val} / \mathrm{Ile}) \text {-Pro-Gly-Xxx-Gly }]_{n}$ display temperature dependent phase behaviour, possessing a so-called lower critical solution temperature (LCST) above which the polypeptide changes shape from random coil to $\beta$-spiral conformation, with a concomitant change from hydrophilic to hydrophobic character. The position of this transition is determined by the polarity of the $\mathrm{Xxx}$ residue. Consequently, in a genetic engineering strategy a perfectly defined copolymer was prepared containing a hydrophilic [ValPro-Gly-Glu-Gly-(Ile-Pro-Gly-Ala-Gly) $\left.{ }_{4}\right]_{14}$ block connected to a lipophilic [Val-Pro-Gly-Phe-Gly-(Ile-Pro-Gly-Val-Gly) $\left.{ }_{4}\right]_{16}$ block. The entire structure was amphiphilic as the first block was below its transition temperature in contrast to the latter block which was

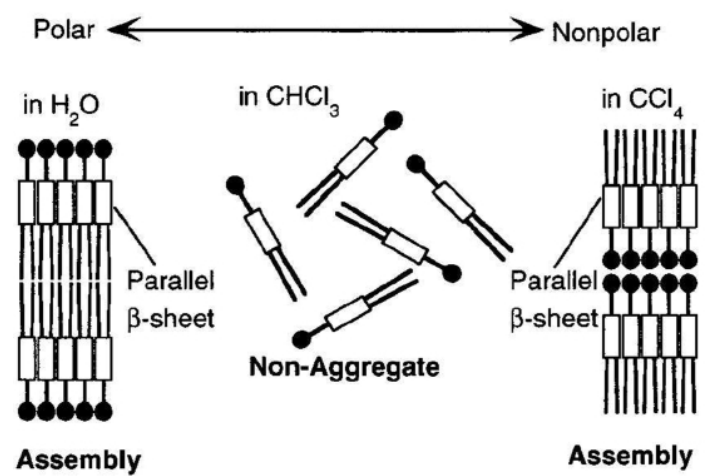

Fig. 20 Schematic illustration of assembling behaviour of the tripeptide containing tripeptide amphiphiles in solution. Reprinted with permission from (ref. 36). Copyright 2000 American Chemical Society.

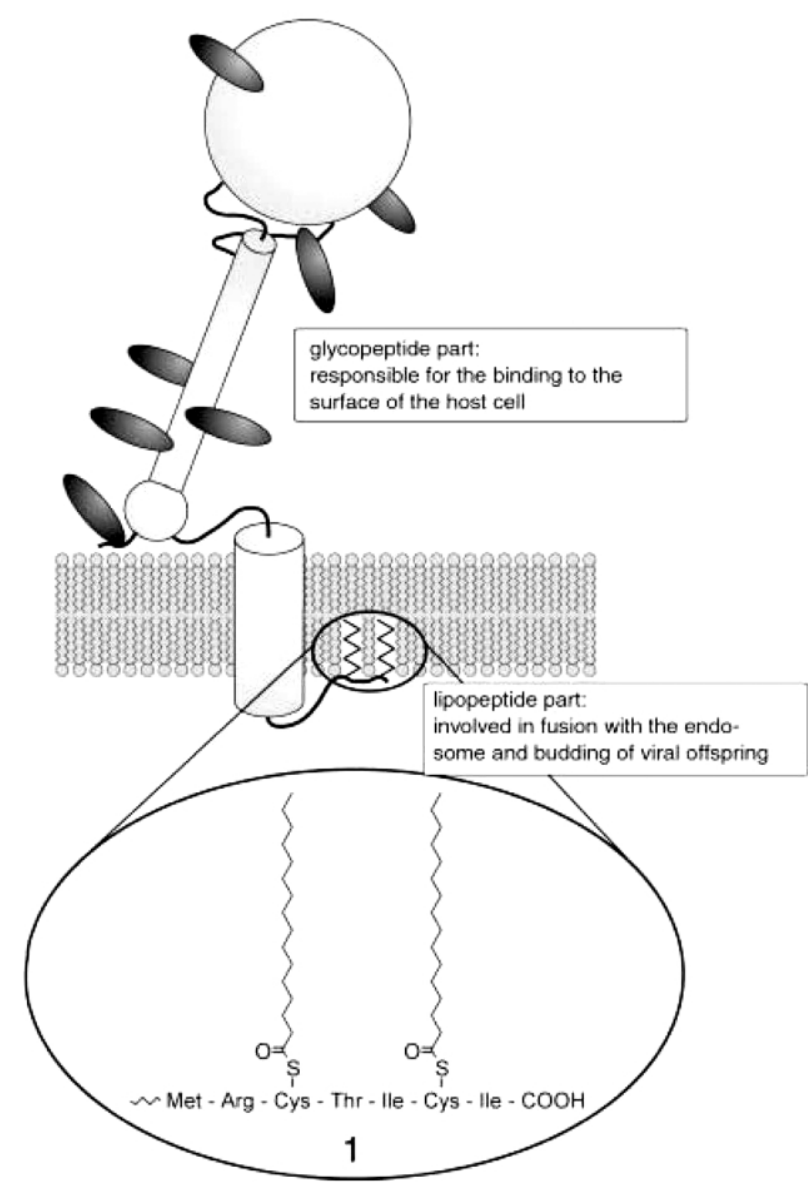

Fig. 21 Schematic drawing of glycosylated and lipidated influenza virus A hemagglutinin and doubly palmitoylated target peptide 1 studied by Eisele et al. Reprinted with permission from (ref. 37). Copyright 2002 Wiley$\mathrm{VCH}$.

above its LCST. This amphiphilic artificial protein was shown to form micelles and cylindrical micelles, and was responsive towards changes in $\mathrm{pH}$ and temperature. Interestingly, all these selfassembly processes are reversible. The elastin-mimetic materials, which seem biocompatible and possess tuneable properties, are<smiles>[R]C(NC(=O)CCCCCCCCCC[N+](C)(C)C)C(=O)NC([R])C(=O)NC(CCC(=O)OCCCCCCCCCCCC)C(=O)OCCCCCCCCCCCCCC</smiles>

Fig. 19 General structure of N- and C-terminally modified tripeptide-based amphiphiles. 
under investigation as candidates for drug delivery and release applications.

A second approach that yields all peptide block copolymers has been developed by Deming, in order to obtain materials that might be used in the development of drug delivery systems. ${ }^{39}$ Traditionally amino acid polymers are conveniently prepared by $N$ carboxyanhydride (NCA) polymerizations initiated by primary amines or alkoxides, however without much control over molecular weight distribution and polymer architecture. More recently, to improve control over the growing polymer chain ends during polymerization, transition metal catalysis has been employed in NCA polymerizations. Nickel and cobalt initiators have been developed that allow for the living polymerization of NCAs to produce polypeptides with narrow molecular weight distributions and controlled molecular weights. Furthermore, by the subsequent addition of different NCA monomers it was possible to generate block copolypeptides of defined composition and with different polarities of the blocks. The appropriate choice of amino acid monomers will therefore lead to polypeptides that can assemble into ordered nanostructures that might be able to bind and encapsulate drugs. Nowak et al..$^{40}$ have, for example, prepared block-copolypeptides with polylysine or polyglutamic acid domains, highly charged polyelectrolytes at neutral $\mathrm{pH}$ that dissolve readily in water, combined with hydrophobic domains that can adopt regular conformations and aggregate in water, namely rodlike $\alpha$-helices for polyleucine and crystalline $\beta$-sheets for polyvaline. Many of these diblock amphiphiles were found to form rigid hydrogels during attempts to dissolve them in water.

Moreover, NCA chemistry can be utilized to produce polypeptide-(non-polypeptide) block copolymers if an amino functionalized synthetic polymer is used as initiator. In this manner di- and triblock polypeptide-polymer hybrids such as polybutadiene- $b$ poly(L-glutamic acid) and poly-( $\gamma$-benzyl-L-glutamate)- $b$-poly(ethylene glycol)- $b$-poly-( $\gamma$-benzyl-L-glutamate) have been prepared and extensively studied by Klok and co-workers ${ }^{41}$ and were shown to form well defined vesicular structures in water. For example, the diblock polymer was prepared by successive anionic polymerization of butadiene followed by an $N$-carboxyanhydride ring-opening polymerization to yield the polypeptide. The critical aggregation concentration was determined to be $10^{-6} \mathrm{M}$, typical for such an amphiphilic block copolymer. As for poly(L-glutamic acid) homopolymers, a $\mathrm{pH}$ dependent folding of the peptide block was found, going from $\alpha$-helical at $\mathrm{pH} 4.5$ to random coil at $\mathrm{pH} 11.5$, as evidenced by circular dichroism spectroscopy. The structural changes were also reflected in the size of the aggregates, increasing with $50 \%$, as the polypeptide conformation changed from a compact $\alpha$-helical structure to a more extended random coil.

Recently, a novel alternative strategy has been presented to prepare peptide-polymer conjugates. ${ }^{42}$ On a solid support first a peptide was synthesized by standard solid phase peptide chemistry from which nitroxide-mediated living free radical polymerizations were initiated to yield a structure as shown in Fig. 22. The entire solid phase approach allows for the preparation of peptide-polymer hybrids, not hampered by separate preparation and coupling of either segment and circumventing solubility issues when combining peptides and synthetic polymers. From such materials it is expected that new biocompatible materials will emerge with highly tuneable properties.

Combining synthetic polymers as hydrophobic tails with an enzyme as head group has led to the development of a new class of amphiphilic molecules, also denoted as giant amphiphiles (Fig. 23). ${ }^{43}$ Lipase B from Candida antarctica, was employed as the

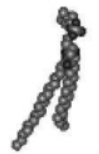

(a) molecular amphiphile
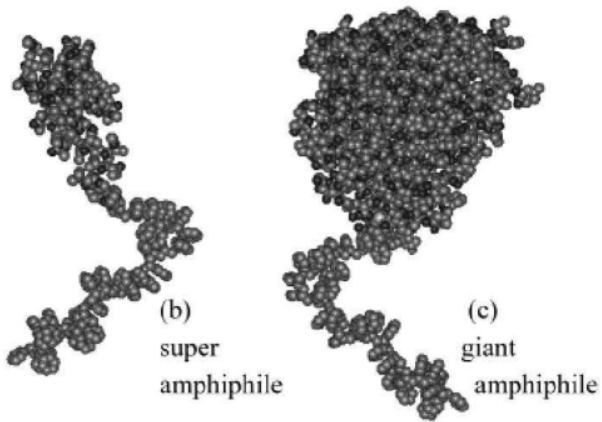

Fig. 23 Computer-generated models of (a) a phospholipid representing the class of molecular amphiphiles (molecular volume $\sim 0.5 \mathrm{~nm}^{3}$, molecular weight $\sim 1 \mathrm{kDa}$ ), (b) a diblock polymer of polystyrene and a polyisocyanopeptide representing the class of super-amphiphiles (molecular volume $\sim 6.5 \mathrm{~nm}^{3}$, molecular weight $\sim 6 \mathrm{kDa}$ ), and (c) the lipasepolystyrene $(n=40)$ biohybrid representing the new class of giant amphiphiles (molecular volume $\sim 25 \mathrm{~nm}^{3}$, molecular weight $\sim 40 \mathrm{kDa}$ ). Reprinted with permission from (ref. 43). Copyright 2002 American Chemical Society.

head group. This protein was coupled to maleimide functionalized polystyrene, after reduction of a surface exposed disulfide bridge. Remarkably, these superamphiphiles self-assembled in a comparable manner to their low-molecular weight counterparts. It was proposed that the fibres the amphiphiles aggregated into, were composed of micellar rods with a hydrophobic polystyrene interior and protein exposed to the aqueous exterior. Whether the aggregation affects the folding of the protein, as is seen often with low molecular weight peptide amphiphiles, was not reported. However, it was found that the catalytic activity of the enzyme was reduced 15-fold, which was ascribed to a destabilizing effect of the hydrophobic polystyrene tail on the active conformation and a possible lower accessibility of the active site.

Distinctly, an even more artificial system was developed by Cornelissen et al. combining a polystyrene tail with a dipeptidebased polyisocyanide head group (Figs. 24 and 25). ${ }^{44}$ Amine functionalized polystyrene, obtained via anionic polymerization to afford a low polydispersity, was used to initiate the polymerization of dipeptide derived isocyanides. The polyisocyanide fragment displayed a helical structure, also observed in other polyisocyanides. Upon optimizing $\mathrm{pH}$, these block copolymers also formed micellar rods, now, consisting of a polystyrene core and polyisocyanide corona. It was found that upon adjusting the length of the polyisocyanide block from 20 to 10 monomer units, the morphology changed to bilayer-type structures and super-helices. It will be interesting to see whether the mechanisms by which these higher-order structures form are similar to those of their small molecule analogues.

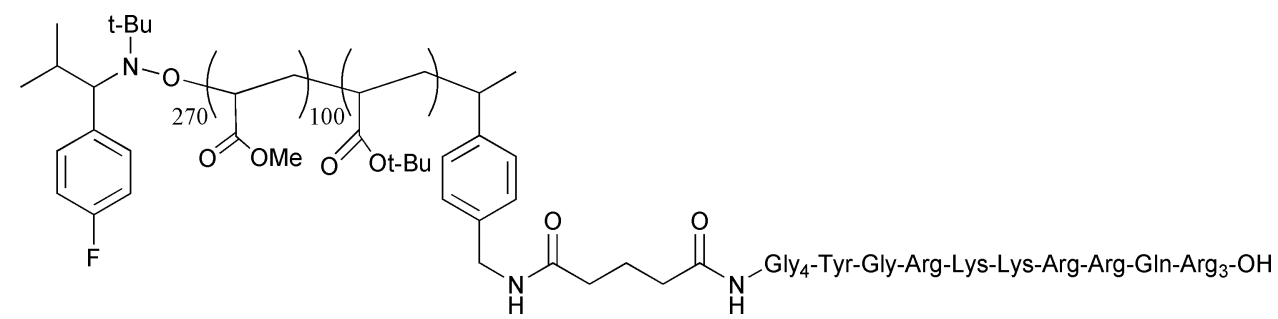

Fig. 22 A synthetic block copolymer prepared on the solid phase, accomplished by coupling an alkoxyamine NMRP initiator to the peptide sequence followed by sequential living radical addition polymerizations. 
A

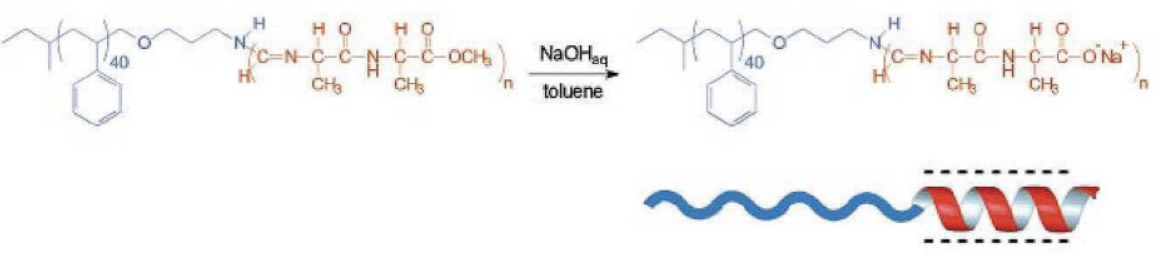

B
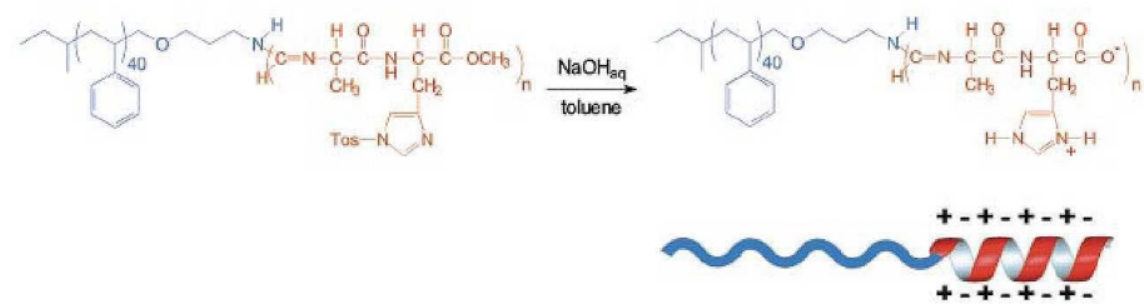

Fig. 24 Deprotection of the block copolymers (A) PS- $b$-PIAA to negatively charged superamphiphiles and (B) PS- $b$-PIAH to zwitterionic superamphiphiles. The $>\mathrm{C}=\mathrm{N}-t$-Bu unit has been omitted for reasons of clarity. Reprinted with permission from (ref. 44). Copyright 2001 AAAS.

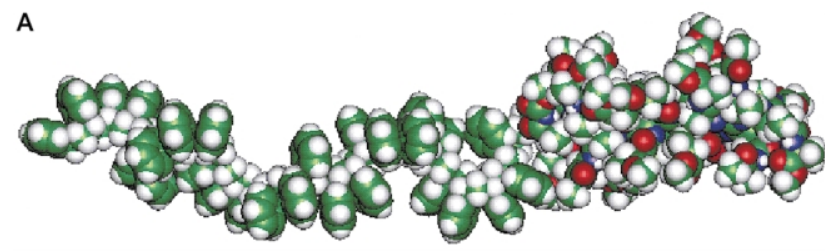

Fig. 25 Computer-generated representation of PS- $b$-PIAA. Reprinted with permission from (ref. 44). Copyright 2001 AAAS.

\section{Concluding remarks}

Although amphiphilic peptides have been a source of inspiration for chemists for considerable amount of time, quite recently the activities within this area have been intensified considerably. The availability of new synthetic methodologies that offer the opportunity to quickly prepare a wide variety of well-defined peptides and their derivatives as well as improved insights in the usefulness of peptide assembly, from both a biomedical and a materials point of view, can be regarded as two developments that partly explain this increased interest. The current research activities have already led to an improved understanding of the design criteria that govern assembly processes in amphiphilic peptides. Due to the complexity of these processes however, there is still room for improvement and, definitely, more research will be required to gain more insight into the way aggregation and peptide secondary structure influence each other, two important factors in the properties of the structures that might be obtained. Remarkably, a lot of the synthetic peptide amphiphiles that have been explored with very interesting properties, although often bio-inspired, do not seem to have an equivalent in nature. The foresight of constructing tailor made self-assembling peptides, with high levels of structural and functional control has such a high potential in especially biomedical applications that activities can be expected to continue or even expand, leading to many more exciting examples of amphiphilic peptide architectures.

\section{References}

1 Y.-Y. Luk and N. L. Abbott, Curr. Opin. Colloid Interface Sci., 2002, 7, 267.

2 e.g. M. L. de la Paz, K. Goldie, J. Zurdo, E. Lacroix, C. M. Dobson, A. Hoenger and L. Serrano, PNAS, 2002, 99, 16052.

3 K. Matsuzaki, Biochim. Biophys. Acta, 1999, 1462, 1.

4 E. J. Prenner, R. N. A. H. Lewis and R. N. McElhaney, Biochim. Biophys. Acta, 1999, 1462, 201.

5 M. Vankann, J. Möllerfeld, H. Ringsdorf and H. Höcker, J. Colloid Interface Sci., 1996, 178, 241.
6 G. von Maltzahn, S. Vauthey, S. Santoso and S. Zhang, Langmuir, 2003, 19, 4332 .

7 H. Rapaport, K. Kjaer, T. R. Jensen, L. Leiserowitz and D. A. Tirrell, J. Am. Chem. Soc., 2000, 122, 12523.

8 E. T. Powers, S. I. Yang, C. M. Lieber and J. W. Kelly, Angew. Chem. Int. Ed., 2002, 41, 127.

9 G. Xu, W. Wang, J. T. Groves and M. H. Hecht, PNAS, 2001, 98, 3652.

10 J. P. Schneider, D. J. Pochan, B. Ozbas, K. Rajagopal, L. Pakstis and J. Kretsinger, J. Am. Chem. Soc., 2002, 124, 15030.

11 R. F. Epand, R. I. Lehrer, A. Waring, W. Wang, R. Maget-Dana, D. Lelièvre and R. M. Epand, Biopolymers, 2003, 71, 2.

12 D. T. Bong, T. D. Clark, J. R. Granja and M. R. Ghadiri, Angew. Chem. Int. Ed., 2001, 40, 988.

13 S. Fernandez Lopez, H. S. Kim, E. C. Choi, M. Delgado, J. R. Granja, A. Khasanov, K. K. G. Long, D. A. Weinberger, K. M. Wilcoxen and M. R. Ghadiri, Nature, 2001, 412, 452.

14 K. Hinterding, D. Alonso-Díaz and H. Waldmann, Angew. Chem. Int. Ed., 1998, 37, 688.

15 K. Barbeau, E. L. Rue, K. W. Bruland and A. Butler, Nature, 2001, 413, 409.

16 M. Rainaldi, A. Moretto, C. Peggion, F. Formaggio, S. Mammi, E. Peggion, J. A. Galvez, M. D. Díaz-de-Villegas, C. Cativiela and C. Toniolo, Chem. Eur. J., 2003, 9, 3567.

17 F. Peypoux, J. M. Bonmatin and J. Wallach, Appl. Microbiol. Biotechnol., 1999, 51, 553.

18 Y.-C. Yu, M. Tirrell and G. B. Fields, J. Am. Chem. Soc., 1998, 120, 9979.

19 P. Forns, J. L. Lauer-Fields, S. Gao and G. B. Fields, Biopolymers, 2000, 54, 531 .

20 J. D. Hartgerink, E. Beniash and S. I. Stupp, Science, 2001, 294, 1684.

21 S. E. Martin and B. R. Peterson, Bioconjugate Chem., 2003, 14, 67.

22 Q. Huo, G. Sui, P. Kele and R. M. Leblanc, Angew. Chem. Int. Ed., 2000, 39, 1854.

23 Q. Huo, G. Sui, Y. Zheng, P. Kele, R. M. Leblanc, T. Hasegawa, J. Nishijo and J. Umemura, Chem. Eur. J., 2001, 7, 4796.

24 H. Seong, W.-M. Choi, J.-C. Kim, D. H. Thompson and K. Park, Biomaterials, 2003, 24, 4487.

25 M. Mrksich, Chem. Soc. Rev., 2000, 29, 267.

26 K. Ariga and T. Kunitake, Acc. Chem. Res., 1998, 31, 371.

27 R. Neumann, H. Ringsdorf, E. V. Patton and D. F. O'Brien, Biochim. Biophys. Acta, 1987, 898, 338.

28 W. Prass, H. Ringsdorf, W. Bessler, K.-H. Wiesmüller and G. Jung, Biochim. Biophys. Acta, 1987, 900, 116.

29 Y.-C. Yu, T. Pakalns, Y. Dori, J. B. McCarthy, M. Tirrell and G. B. Fields, Methods Enzymol., 1997, 289, 571.

30 N. Yagi, Y. Ogawa, M. Kodaka, T. Okada, T. Tomohiro, T. Konakahara and H. Okuno, Chem. Commun., 1999, 1687.

31 T. Pakalns, K. L. Haverstick, G. B. Fields, J. B. McCarthy, D. L. Mooradian and M. Tirrell, Biomaterials, 1999, 20, 2265.

32 V. Marchi-Artzner, B. Lorz, U. Hellerer, M. Kantlehner, H. Kessler and E. Sackmann, Chem. Eur. J., 2001, 7, 1095.

33 B. Pfeiffer, E. Peduzzi, K. Moehle, R. Zurbriggen, R. Glück, G. Pluschke and J. A. Robinson, Angew. Chem. Int. Ed., 2003, 42, 2368. 
34 H. Ihara, T. Fukumoto, C. Hirayama and K. Yamada, Polym. Commun., 1986, 27, 282.

35 D. W. P. M. Löwik, J. G. Linhardt, P. J. H. M. Adams and J. C. M. van Hest, Org. Biomol. Chem., 2003, 1, 1827.

36 K. Ariga, J. Kikuchi, M. Naito, E. Koyama and N. Yamada, Langmuir, 2000, 16, 4929

37 F. Eisele, J. Kuhlmann and H. Waldmann, Chem. Eur. J., 2002, 8, 3362.

38 E. R. Wright and V. P. Conticello, Adv. Drug Delivery Rev., 2002, 54, 1057.
39 T. J. Deming, Adv. Drug Delivery Rev., 2002, 54, 1145

40 A. P. Nowak, V. Breedveld, L. Pakstis, B. Ozbas, D. J. Pine, D. Pochan and T. J. Deming, Nature, 2002, 417, 424.

41 F. Chécot, S. Lecommandoux, Y. Gnanou and H. A. Klok, Angew. Chem. Int. Ed., 2002, 41, 1339.

42 M. L. Becker, J. Liu and K. L. Wooley, Chem. Commun., 2003, 180.

43 K. Velonia, A. E. Rowan and R. J. M. Nolte, J. Am. Chem. Soc., 2002, 124, 4224.

44 J. J. L. M. Cornelissen, M. Fischer, N. A. J. M. Sommerdijk and R. J. M. Nolte, Science, 1998, 280, 1427. 